\title{
SOME EXPERIMENTS ON THE RESISTANCE OF GYPSY MOTH EGGS TO THE DIGESTIVE FLUIDS OF BIRDS.
}

\section{By William Reiff. ${ }^{1}$}

The subject of the present paper has already been referred to in a previous article published in one of the recent numbers of this journal. There I referred to the investigations of Alexander Bau who determined by numerous experiments that the eggs of certain species of Lepidoptera will pass out undigested, and still remain in a living state after a trip through the stomach and intestines of some species of birds. On this account I thought that Gypsy Moth eggs which have extremely hard chitinous shells, might readily withstand such a journey without damage. If this should prove true the sporadic diffusion of the Gypsy Moth in New England, which has hitherto been so mysterious, might find a partial explanation.

In selecting the birds used for these experiments it proved impossible to get native species and I was compelled to substitute foreign birds such as sparrows and finches. Altogether species belonging to the following four families were utilized:

Fringillidæ. (German Canary Bird, English Yellow Hammer and English Chaffinch.)

Turdidæ. (Japanese Robin.)

Bubonidæ. (Screech Owl.)

Columbidæ. (Carrier Pigeon.)

\section{German Canary Bird.}

One dispar egg cluster overwintered in outside temperature was divided into two parts early in March, 1910. One half was put apart for control while the other was separated into its individual eggs. The eggs were put into small crumbs of bread to which small pieces of cochineal were added for the purpose of tracing the eggs in the droppings of the bird. The food thus prepared was given to the bird early in the morning and had passed through the alimentary tract at the expiration of an hour and twenty minutes. All

\footnotetext{
1 Contributions from the Entomological Laboratory of the Bussey Institution, Harvard University, No. 24.
} 
the red excrement was collected the same afternoon and dried in the air for two days. To facilitate the hatching of the caterpillars from such eggs as might be contained in the excrement, this was carefully broken into small pieces. Seven eggs were found but each had the shell slightly injured by the bird's beak. The rest of the eggs had not been eaten but had been picked out of the crumbs of bread by the bird and thrown aside. The hatching of caterpillars from the control eggs began on March 21 and was completed two days later, but the seven eggs obtained from the excrement failed to hatch, having dried up.

In the following experiments the same precautions were taken, keeping control eggs from each cluster used and adding bits of cochineal so that this need not be mentioned in the case of the other birds.

\section{English Chaffinch}

A bird of this species was fed in the same way but the eggs were not passed in the excrement until nearly three hours after feeding. The excrement was dried and broken up as before but not a single dispar egg could be found. These missing eggs were later found uneaten, having been cast aside by the bird.

\section{English Yellow Hammer.}

A specimen of this species was fed as before but the eggs were placed in living larvæ of the meal-beetle which had been cut open on the last four abdominal segments to insert the Gypsy Moth eggs. The bird was fed with these in the morning and after an hour and a half they were passed in the excrement of the bird. In this case twelve dispar eggs were found and no sort of injury could be detected on any of them. Other eggs fed in pieces of bread were cast aside by the bird and not eaten. Although the caterpillars from the control eggs hatched normally all those fed to the bird failed to hatch. These changed color normally but died with a nearly developed caterpillar in each egg.

\section{Japanese Robin.}

This bird was fed on eggs placed in meal-beetle larvæ as was done with the previous bird. The bird was fed late in the morning and an hour and a half later the eggs were passed in its red excre- 
ment. Fifty-two eggs were found in this excrement and of these one hatched on the 23rd of March, followed by two on the morning of the 24th. A later investigation showed fully developed caterpillars in the eggs which had failed to hatch.

\section{Screech Orel.}

I at first attempted to feed the owl on bits of chopped beef in which eggs had been placed but it refused to partake of this mixture. It was then allowed to fast for a couple of days after which I offered it a freshly killed mouse into which one hundred and twenty dispar eggs had been placed through an incision made in the abdomen. This prepared mouse was given to the bird late one afternoon and was eaten during the following night. Late the next afternoon I found the red colored vomitings composed of the indigestible parts of the mouse and these contained a considerable number of dispar eggs, although none could be detected in the excrement. Altogether I found one hundred and twelve eggs, every one without any sign of injury. At the same time that the control eggs began to hatch some of those obtained from the owl gave forth caterpillars until altogether seven appeared. All of the others failed to hatch although they changed color in a normal way.

\section{Carrier Pigeon.}

This bird was fed upon a mixture of boiled pigeon-food to which the Gypsy Moth eggs were added. This was given to the pigeon late in the morning and after three hours had passed through its alimentary tract. Quite a number of eggs had been eaten by the pigeon but none was found in the excrement.

To sum up the details of these various experiments it is seen that Gypsy Moth eggs can withstand the action of the digestive fluids of birds belonging to at least two families, Turdidæ and Bubonidæ, without suffering any, or only slight, injury. In regard to the large family, Fringillidæ, also an insectivorous group, I am inclined to believe that these birds might also occasionally distribute Gypsy Moth eggs in spite of the negative results obtained in my experiments. Since the members of the pigeon family grind up their food in a gizzard filled with small stones it is very unlikely that Gypsy 
Moth eggs could pass through their intestines without being destroyed.

In conclusion I wish to express my hearty appreciation to Prof. W. M. Wheeler, Prof. W. E. Castle and Dr. A. L. Reagh for their advice and assistance.

\title{
GEOMETRID NOTES.
}

\author{
By L. W. Swetr, \\ Boston, Mass. \\ A New Cingilia.
}

Cingilia rubiferaria, sp. nov.

Expands $\sigma^{\circ}$ 32-33 mm., of 24-25 mm. Fore wings slate colored and semihyaline much thinner in texture than in C. catenaria, due to the much fewer scales and further apart, also more hairy. In some specimens the color is smoky brown but not so prevailing as the slate color. Front of head bright ocher as are tufts on thorax, but body is gray. First markings start on costa one fourth out, notched on each vein and black same as catenaria but not so distinct while it is always plain in the latter. Discal spot black, beyond extra discal lines runs zig-zag notched on the veins as catenaria. Black dots at ends of veins in fringe which is dusky. Hind wings same color as fore, with single extra discal notched line and dots at ends of veins. Beneath same as above only the lines are just visible which is not true of catenaria where they are strong. The female is strikingly different from the male being about one half the size and presents rather the appearance of a moth whose wings never fully expanded. The body is extremely heavy for the size of the moth and it is doubtful if it can fly. The markings are the same as the male except from the extra discal line on fore and hind wings the veins are black to outer border. Beneath same markings as above the black veins running from extra discal lines on fore and hind wings to inner margin.

I was at first inclined to place this as a melanic race of catenaria, it not being found in any place outside of Attean Pond, Maine, so Mr. Lucas tells mé, and he examined the vicinity, nor did he take any catenaria at the same place. The small size female and the more hairy and thinner scaled wings would serve to separate it from catenaria and also the hairs appear broader under the microscope giving the wings a transparent look. This species was taken by Mr. Lucas at Attean Pond in northern Maine near Moosehead 

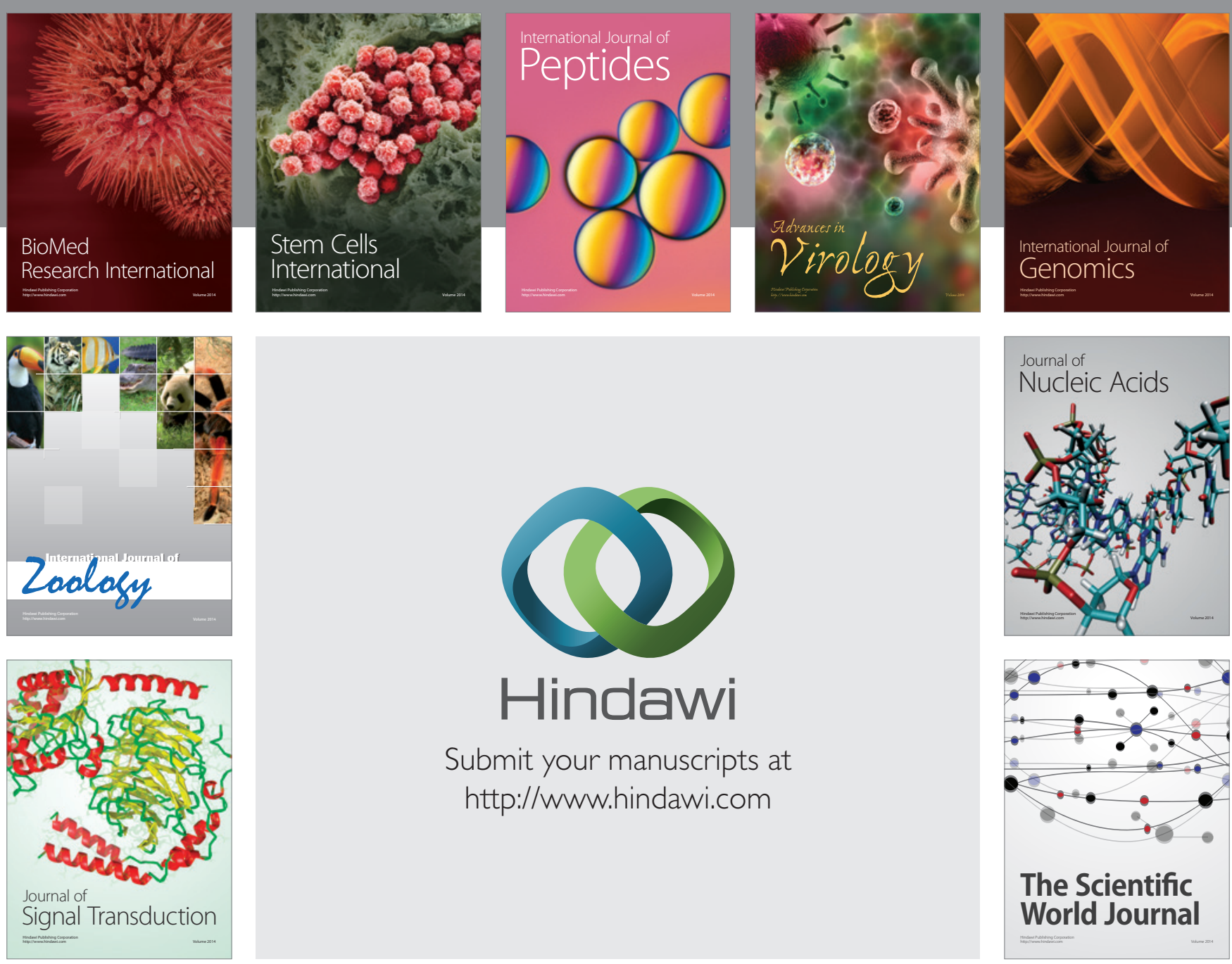

Submit your manuscripts at

http://www.hindawi.com
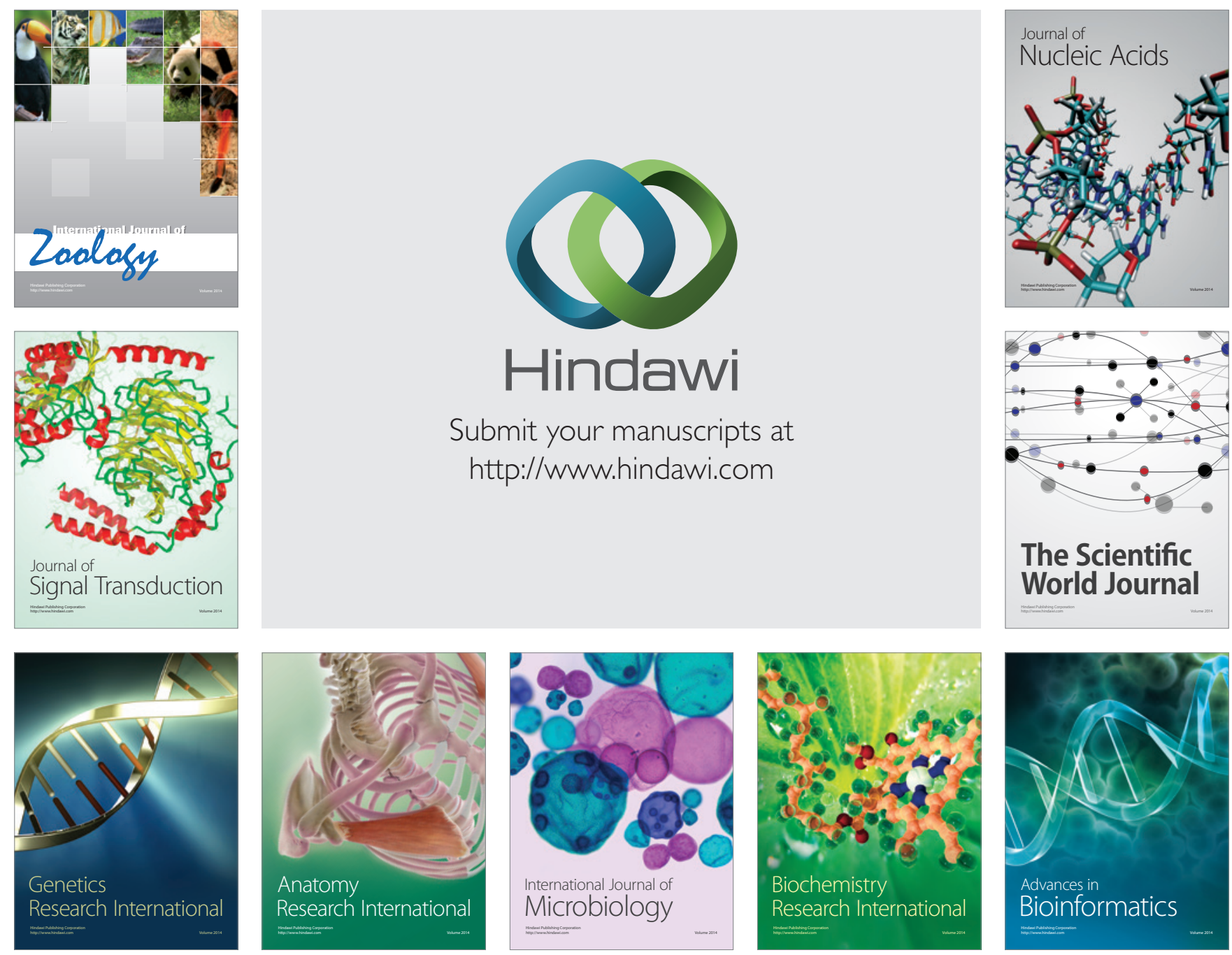

The Scientific World Journal
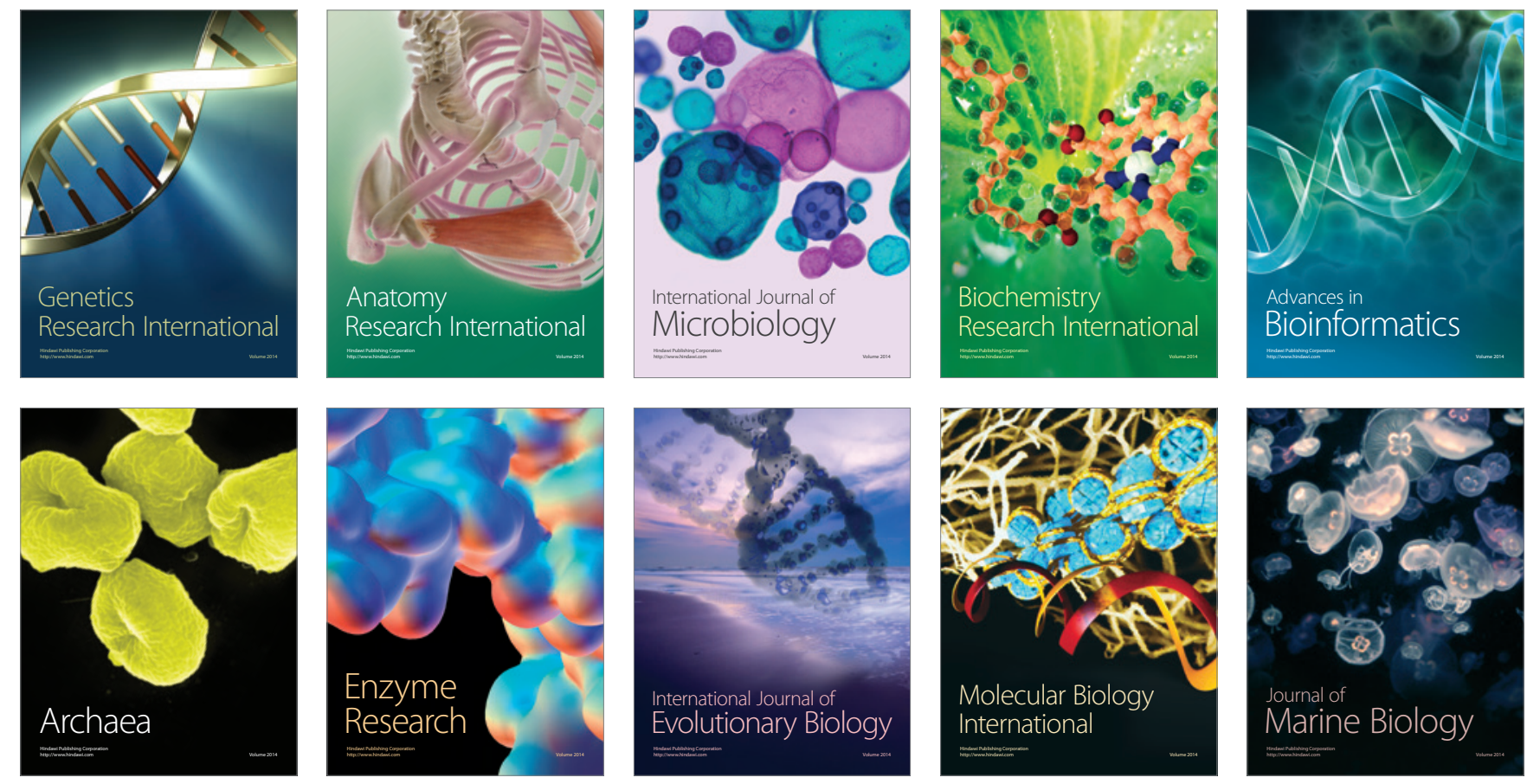